\title{
Surgical expertise and hip osteotomies
}

\author{
S. Thomas
}

Received: 5 February 2008 / Accepted: 7 February 2008 / Published online: 11 March 2008

(C) Springer-Verlag 2008

\section{Dear Editor,}

The article by Haverkamp et al. [1] has been read with great interest. We have to agree with the authors that proximal femoral osteotomy is on the decline. This is due to several factors as stated by the authors, as well the declining surgical expertise for performing hip osteotomies.

In this era, where patient satisfaction is given importance and with the ever booming advances of total hip arthroplasties, it is only natural for surgeons to choose an operation with which they are well versed and can ensure excellent results and patient satisfaction. The availability of information on the Internet and the contradictory results of proximal femoral osteotomies further add to the fact that patients prefer a total joint replacement to osteotomy [2,3]. Osteotomies, especially around the acetabulum, are techni- cally demanding and should only be carried out in specialist centres. All these factors collectively contribute to the declining use and surgical expertise for hip osteotomies.

\section{References}

1. Haverkamp D, Eijer H, Besselaar PP, Marti RK (2008) Awareness and use of intertrochanteric osteotomies in current clinical practice. An international survey. Int Orthop 32:19-25

2. Shigematsu M, Hotokebuchi $T$ (2007) Total hip arthroplasty after previous proximal femoral osteotomy. Clin Calcium 17(6): 947-953

3. Suzuki K, Kawachi S, Matsubara M, Morita S, Jinno T, Shinomiya K (2007) Cementless total hip replacement after previous intertrochanteric valgus osteotomy for advanced osteoarthritis. J Bone Joint Surg Br 89(9):1155-1157 